\title{
A Case Report of Lipid-Rich Carcinoma of the Breast Including Histological Characteristics and Intrinsic Subtype Profile
}

\author{
Ayako Kimura $^{\mathrm{a}}$ Hisanori Miki ${ }^{\mathrm{a}}$ Takashi Yuri $^{\mathrm{a}}$ \\ Takehiko Hatano $^{\text {b }}$ Airo Tsubura ${ }^{\mathrm{a}}$
}

aDepartment of Pathology II, Kansai Medical University, Moriguchi, and ${ }^{\mathrm{b}}$ Division of Breast Surgery, Katano Hospital, Katano, Japan

\section{Key Words}

Lipid-rich carcinoma - Lipid-secreting carcinoma - Breast cancer · Intrinsic subtypes . Immunohistochemistry

\begin{abstract}
A 57-year-old Japanese woman with schizophrenia, who had received long-term treatment with neuroleptics, noticed a painless, pea-sized lump in her right breast. She was admitted to our hospital and a malignant tumor was diagnosed. The patient underwent a conservative radical mastectomy (Patey's operation). The excised tumor measured $2.0 \times 1.2 \times 1.1 \mathrm{~cm}$ in diameter, and its cut surface was grayish-white. Histologically, tumor cells with clear to foamy cytoplasm were invariably Oil Red Opositive and periodic acid Schiff-negative with or without diastase digestion. The tumor was diagnosed as a lipid-rich carcinoma accompanied by an in situ component. Neuroleptics increase serum prolactin levels by interfering with dopaminergic inhibition of prolactin secretion. Immunohistochemical analysis revealed that, although prolactin was not detected, the tumor cells expressed prolactin receptor, indicating prolactin as the genesis of this neoplasm. In immunohistochemical intrinsic subtype analysis, the tumor was negative for estrogen receptor, progesterone receptor, human epidermal growth factor receptor 1 and 2, and basal cytokeratins (CK5, CK6, and CK14), indicating an unclassified (all-marker negative) subtype. Axillary lymph nodes were free of metastasis (stage I), and the patient has been well for 20 years without any evidence of recurrence.
\end{abstract}




\section{Introduction}

Lipid-rich carcinoma is a very rare histological variant of breast cancer that accounts for less than $1 \%$ of all breast cancers [1]. It is composed of clear to vacuolated cytoplasm with abundant neutral lipid present within $90 \%$ of the tumor cells [2]. Lipid-rich carcinomas are considered to behave aggressively and have a worse prognosis than other types of breast cancer. However, the true behavior of this tumor is not well known. Gene expression profiling studies have refined breast cancer classification and identified distinct subgroups that have an independent association with patient outcome [3,4], and findings can be surrogated by immunohistochemical markers that match the gene expression patterns [5-7]. Here, a case of lipid-rich carcinoma previously included as case 1 in a series of 13 breast cancer patients who received long-term treatment with neuroleptics [8] was re-evaluated to determine the intrinsic immunohistochemical (IHC) subtype. The present report describes the histological characteristics and intrinsic subtype profile of this case of lipid-rich carcinoma of the breast.

\section{Case Report}

A 57-year-old Japanese woman who had received long-term neuroleptic treatment for schizophrenia noticed a painless, pea-sized lump in her right breast, and she was admitted to our hospital. The tumor size was $2.5 \times 1.5 \mathrm{~cm}$ in diameter, and an excisional biopsy confirmed malignancy (T1N0M0). The patient underwent a conservative radical mastectomy (Patey's operation: $\mathrm{Br}+\mathrm{Ax}+\mathrm{Mn}$ ). The excised tissue specimens were routinely processed for histological, histochemical, and IHC examinations. Briefly, formalin-fixed, paraffin-embedded tissues were deparaffinized and stained with hematoxylin and eosin (HE) and periodic acid-Schiff (PAS) with or without diastase digestion.

Immunohistochemistry was performed with the primary antibodies listed in table 1 and a labeled streptavidin biotin staining kit (Dako, Carpinteria, Calif., USA). Frozen sections cut on a cryostat were prepared from the formalin-fixed wet tissues and stained with Oil Red O.

Macroscopically, the excised tumor measured $2.0 \times 1.2 \times 1.1 \mathrm{~cm}$ in diameter, and its cut surface was grayish-white. Histologically, tumor cells were large with clear to foamy cytoplasm, accompanied by cellular pleomorphism and nuclear atypia. Cancer cells were arranged irregularly in solid clumps and nests (fig. 1a) or formed atypical epithelial tufts that protruded into the lumen with desquamated cells within the lumen (fig. 1b). Cancer cells were invariably Oil Red O-positive (fig. 1c and d) and PASnegative. Immunohistochemically, the tumor cell membranes were positive for E-cadherin (fig. 2a) but the tumor cell cytoplasm was negative for basal cytokeratins (CK5, CK6, and CK14). However, basal (myoepithelial) cells surrounding the glandular lumen composed of apocrine extrusion of the nuclei were positive for CK5 (fig. 2b), CK14, and $\alpha$-smooth muscle actin ( $\alpha$-SMA). Cancer cells were prolactin (Prl)-negative, whereas the prolactin receptor (PrlR) showed cytoplasmic staining (fig. 2c). Cancer cells were invariably negative for estrogen receptor (ER), progesterone receptor (PgR), epidermal growth factor receptor 1 (HER1), and HER2. Cancer cell invasion was seen in the mammary fat pad, but vessel invasion was not seen. Adjacent non-cancerous mammary gland showed diffuse and extensive secretory activity. All 16 right axillary lymph nodes were free of metastasis. The patient has remained cancer-free for 20 years without any evidence of recurrence.

\section{Discussion}

Prl contributes to the growth of normal and malignant breast tissues. Long-term neuroleptic usage produces a persistent and marked elevation of serum Prl levels, which results in secretory activity in the breast [8]. PrlR is a transmembrane protein that consists of extracellular, transmembrane, and intracellular domains, and Prl acts through the PrlR. Monoclonal antibody B6.2 is directed against the extracellular domain of human PrlR [9]. 
Although cancer cells were Prl-negative, they were positive for PrlR, which indicates that Prl might have played an important role in the development of the lipid-rich carcinoma of the breast mediated through the PrlR pathway. The lipid-rich carcinoma contained a large amount of neutral lipid but did not contain glycogen or mucin. Secretory carcinomas, apocrine carcinomas and glycogen-rich carcinomas are also composed of clear to vacuolated cancer cells. A PAS-negative reaction can differentiate lipid-rich carcinomas from these other histological types of carcinomas. Additionally, in the present case, $\alpha$-lactalbumin was diffusely positive in the cytoplasm of cancer cells lining the glandular lumina [8]. Histologically, lipid-rich carcinomas contain in situ areas and invasive areas. In situ areas contain cells arranged in an alveolar pattern with a hobnail appearance, in which the luminal borders exhibit apocrine-type cytoplasmic blebs and extrusion of hyperchromatic pleomorphic nuclei. Invasive areas contain cells with clear and foamy cytoplasm arranged in sheets, nests, and cords [1, 10,11]. Basal cells in the breast express high-molecular-weight basal CKs including CK5/6 and CK14 [12, 13], and a-SMA is a marker of myoepithelial differentiation [14]. Foci surrounded by basal (myoepithelial) cells indicate an in situ portion, while the lack of these cells indicates an invasive portion. The present lipid-rich carcinoma was accompanied by an in situ portion. Breast cancer can be distinguished as ductal or lobular in nature, and lipid-rich carcinoma can be associated with either ductal or lobular carcinoma in situ [11]. Ecadherin, a transmembrane glycoprotein that binds similar types of cells together, exists in the membranes of cells in ductal lesions while it is lacking in lobular lesions [15]. In the present case, the tumor was E-cadherin positive, which suggests that the carcinoma is ductal in nature. Lipid-rich carcinomas in the form of ductal carcinoma in situ (DCIS) [16] or in the form of an invasive component accompanied with DCIS [17] have been reported.

IHC intrinsic subtypes can be defined by using markers as follows: luminal A (ER+ and/or PgR+, HER2-), luminal B (ER+ and/or PgR+, HER2+), HER2-enriched (ER-, PgR-, HER2+), and triple negative (ER-, PgR-, HER2-). The triple-negative subtype can be further divided into basal-like (ER-, PgR-, HER2-, CK5/6+, and/or HER1+) and unclassified (negative for all five markers) [5-7]. According to this system, the present case is the unclassified subtype. Due to the rarity of lipid-rich carcinomas, the association between intrinsic subtypes and aggressiveness has not been extensively studied. In one study, 5 of 6 (83.3\%) lipid-rich carcinomas were ER+ and/or PgR+, while 3 of 6 (50\%) lipid-rich carcinomas were HER2+ [18]. In a study of 17 lipid-rich carcinomas, 1 tumor was ER+ and/or PgR+, and all 17 carcinomas were HER2+ [19]. In a third study, 5 of 49 (10.2\%) lipid-rich carcinomas were ER+ and/or PgR+ and 35 of 49 (71.4\%) lipid-rich carcinomas were HER2+ [20]. Thus, the positive rate of ER and/or PgR tended to be low, and HER2 expression tended to be high in these studies of lipid-rich carcinomas.

According to IHC intrinsic subtype analysis, patients who have HER2-enriched and triple-negative subtype cancers have a significantly shorter disease-free survival period than patients with other subtypes [7]. The poor prognosis among triple-negative cases is conferred almost entirely in basal-like breast cancer [21]. Breast carcinoma with basal differentiation can be defined based on the expression of basal CK, such as CK5, CK6, and CK14 [13], and lipid-rich carcinoma with a basal cell phenotype (ER-, PgR-, HER2-, high molecular weight $\mathrm{CK}+$, HER1+) has been reported [22]. Although the lipid-rich carcinoma in the present case report was ER- and PgR-negative, it was also negative for HER2 and basal cell CKs, and the patient remains disease-free 20 years after the surgery. 
Therefore, in lipid-rich carcinoma, like in other histologic types of breast carcinomas, HER2 and basal-like subtypes may indicate the aggressive behavior of the neoplasm.

\section{Disclosure Statement}

The authors have no conflicts of interest to declare.

Table 1. Antibodies used in the present study

\begin{tabular}{lll}
\hline Antibody & Clone & Source \\
\hline E-cadherin & M106 & Takara (Otsu, Japan) \\
CK5 & XM26 & Novocastra (Newcastle upon Tyne, UK) \\
CK6 & LHK6B & Novocastra \\
CK14 & LL002 & Novocastra \\
a-SMA & 1A4 & Dako (Glostrup, Denmark) \\
Prl & Polyclonal & Dako \\
PrlR & B6.2 & LifeSpan Biosciences (Seattle, Wash., USA) \\
ER & 6F11 & Novocastra \\
PgR & PR10A9 & Biodesign (Saco, Me., USA) \\
HER1 & EGFR.25 & Novocastra \\
HER2 & Polyclonal & Dako \\
\hline
\end{tabular}




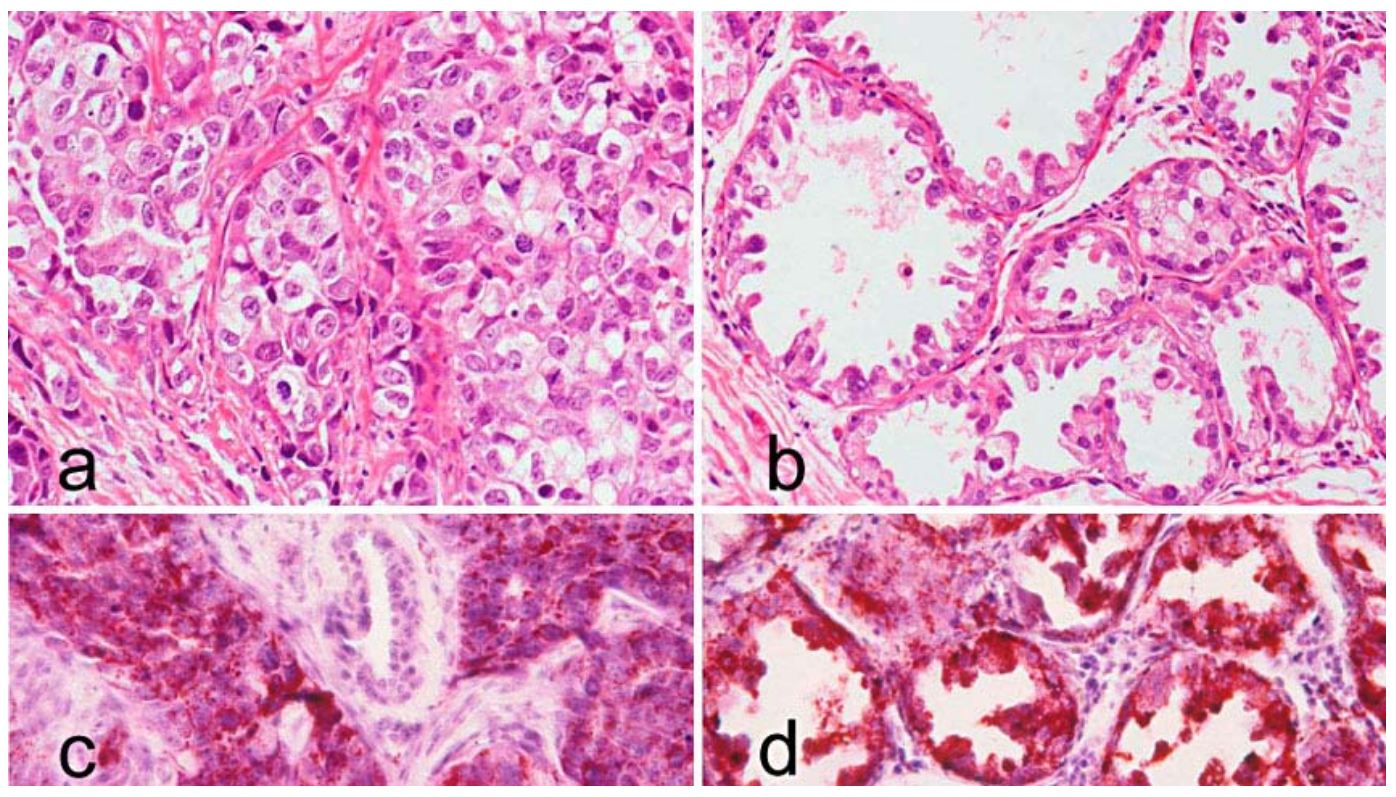

Fig. 1. Lipid-rich carcinoma. a Cancer cells with clear and foamy cytoplasm grow in solid clumps and nests $(\mathrm{HE}, \times 200)$. b Cancer cells arranged in an alveolar pattern with a hobnail appearance show apocrine-type cytoplasmic blebs and extrusion of hyperchromatic pleomorphic nuclei $(\mathrm{HE}, \times 200)$. c Large amounts of lipid are seen in cancer cells arranged in solid clumps and nests (Oil Red O, ×200). d Cancer cells arranged in an alveolar pattern are filled with lipid (Oil Red O, ×200).

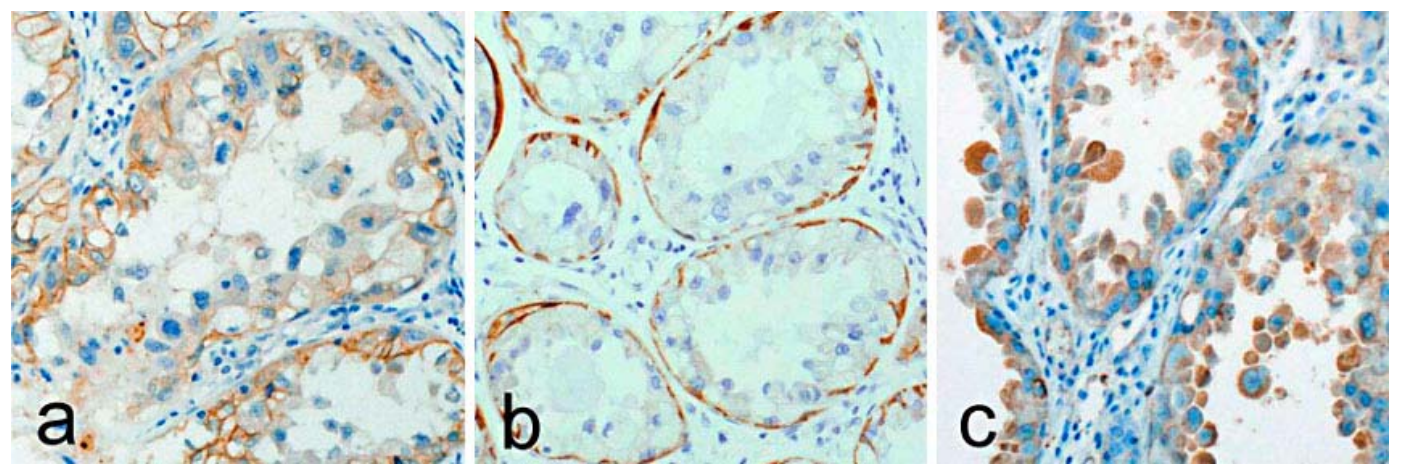

Fig. 2. Lipid-rich carcinoma. a E-cadherin is expressed in cancer cell membranes (E-cadherin, $\times 200$ ). b Cancer cells are CK5-negative, whereas CK5 was positive in basal (myoepithelial) cells $(\mathrm{CK} 5, \times 200)$. c Cytoplasmic prolactin receptor (PrlR) is expressed in cancer cells $(\operatorname{PrlR}, \times 200)$.

\section{References}

1 Rosen PP: Lipid-rich carcinoma; in Rosen PP: Rosen's Breast Pathology, ed 3, Philadelphia, Lippincott Williams and Wilkins, 2009, pp 610-611.

2 Tavassoli FA, Eusebi V: Lipid-rich carcinoma; in Silverberg SG (ed): Tumors of the Mammary Gland. AFIP Atlas of Tumor Pathology. Washington DC, AFIP, 2009, Series 4, Fascicle 10, pp 230-231.

3 Perou CM, Sørlie T, Eisen MB, van de Rijn M, Jeffrey SS, Rees CA, Pollack JR, Ross DT, Johnsen H, Akslen LA, Fluge O, Pergamenschikov A, Williams C, Zhu SX, Lønning PE, Børresen-Dale AL, Brown PO, Botstein D: Molecular portraits of human breast tumours. Nature 2000;406:747-752. 
-4 Sorlie T, Tibshirani R, Parker J, Hastie T, Marron JS, Nobel A, Deng S, Johnsen H, Pesich R, Geisler S, Demeter J, Perou CM, Lønning PE, Brown PO, Børresen-Dale AL, Botstein D: Repeated observation of breast tumor subtypes in independent gene expression data sets. Proc Natl Acad Sci USA 2003;100:8418-8423.

-5 Nielsen TO, Hsu FD, Jensen K, Cheang M, Karaca G, Hu Z, Hernandez-Boussard T, Livasy C, Cowan D, Dressler L, Akslen LA, Ragaz J, Gown AM, Gilks CB, van de Rijn M, Perou CM: Immunohistochemical and clinical characterization of the basal-like subtype of invasive breast carcinoma. Clin Cancer Res 2004;10:53675374 .

-6 Carey LA, Perou CM, Livasy CA, Dressler LG, Cowan D, Conway K, Karaca G, Troester MA, Tse CK, Edmiston S, Deming SL, Geradts J, Cheang MC, Nielsen TO, Moorman PG, Earp HS, Millikan RC: Race, breast cancer subtypes, and survival in the Carolina Breast Cancer Study. JAMA 2006;295:2492-2502.

7 Shibuta K, Ueo H, Furusawa H, Komaki K, Rai Y, Sagara Y, Kamada Y, Tamaki N: The relevance of intrinsic subtype to clinicopathological features and prognosis in 4,266 Japanese women with breast cancer. Breast Cancer 2010, Epub ahead of print.

-8 Tsubura A, Hatano T, Murata A, Shoji T, Shikata N, Morii S: Breast carcinoma in patients receiving neuroleptic therapy. Morphologic and clinicopathologic features of thirteen cases. Acta Pathol Jpn 1992;42:494-499.

-9 Gill S, Peston D, Vonderhaar BK, Shousha S: Expression of prolactin receptors in normal, benign, and malignant breast tissue: an immunohistological study. J Clin Pathol 2001;54:956-960.

10 van Bogaert LJ, Maldague P: Histologic variants of lipid-secreting carcinoma of the breast. Virchows Arch A Pathol Anat Histol 1977;375:345-353.

11 Azzopardi JG, Ahmed A, Millis RR: Lipid-rich carcinoma; in Bennington JL (ed): Problems in Breast Pathology. Major Problems in Pathology Series, vol 11. Philadelphia, WB Saunders, 1979, pp 301-305.

12 Tsubura A, Okada H, Senzaki H, Hatano T, Morii S: Keratin expression in the normal breast and in breast carcinoma. Histopathology 1991;18:517-522.

13 Rakha EA, El-Sayed ME, Green AR, Paish EC, Lee AH, Ellis IO: Breast carcinoma with basal differentiation: a proposal for pathology definition based on basal cytokeratin expression. Histopathology 2007;50:434-438.

14 Tsubura A, Hatano T, Hayama S, Morii S: Immunophenotypic difference of keratin expression in normal mammary glandular cells from five different species. Acta Anat (Basel) 1991;140:287-293.

15 Goldstein NS, Bassi D, Watts JC, Layfield LJ, Yaziji H, Gown AM: E-cadherin reactivity of 95 noninvasive ductal and lobular lesions of the breast: implications for the interpretation of problematic lesions. Am J Clin Pathol 2001;115:534-542.

16 Nagata Y, Hanagiri T, Ono K, Shimokawa H, Yamazaki M, Takenaka M, Yamada S, Yano K, Morita M: A noninvasive form of lipid-secreting carcinoma of the breast. Breast Cancer 2010, Epub ahead of print.

17 Mazzella FM, Sieber SC, Braza F: Ductal carcinoma of male breast with prominent lipid-rich component. Pathology 1995;27:280-283.

-18 Varga Z, Zhao J, Ohlschlegel C, Odermatt B, Heitz PU: Preferential HER-2/neu overexpression and/or amplification in aggressive histological subtypes of invasive breast cancer. Histopathology 2004;44:332-338.

19 Guan B, Wang H, Cao S, Rao Q, Wang Y, Zhu Y, Shi Q, Yin H, Wang X, Zhou X: Lipid-rich carcinoma of the breast clinicopathologic analysis of 17 cases. Ann Diagn Pathol 2011, Epub ahead of print.

20 Shi P, Wang M, Zhang Q, Sun J: Lipid-rich carcinoma of the breast: a clinicopathological study of 49 cases. Tumori 2008;94:342-346.

21 Cheang MC, Voduc D, Bajdik C, Leung S, McKinney S, Chia SK, Perou CM, Nielsen TO: Basal-like breast cancer defined by five biomarkers has superior prognostic value than triple-negative phenotype. Clin Cancer Res 2008;14:1368-1376.

22 Russo S, Coppola D, Vinaccia P, Siciliano A, Baldassarre F, Battista G, Pisani G, Sepe J, Maiello FM: Lipid-rich histology in a basal-type immuno-profile breast carcinoma: a clinicopathological histochemical and immunohistochemical analysis of a case. Rare Tumors 2009;28:e41. 